\title{
RETOS Y RESPUESTAS EN LA GESTIÓN EUROPEA DE LAS AGUAS:LOS SISTEMAS DE RIEGO POR ASPERSIÓN EN EL NOROESTE DE ESPAÑA
}

\author{
David GUILLET
}

Anne Marie HOBBS

Universidad Católica de América. Washington D.C.

\section{INTRODUCCIÓN.}

En todo el mundo, las nuevas demandas de agua, los altos costos de drenaje, la inundación, la salinización y la alcalinización asociada con la irrigación excesiva han llevado a la adopción de sistemas conservadores de agua tales como el riego por aspersión y la irrigación de bajo volumen ${ }^{1}$. En España, la cuenca del río Duero es una región en la que los sistemas de riego por aspersión han sido utilizados ampliamente durante los últimos años. La adopción de los sistemas de riego por aspersión comenzó en la década de los sesenta, y ha surgido desde la década de los setenta en el sur del Duero, principalmente en las provincias de Valladolid, Ávila, Salamanca y Segovia. Los administradores de las grandes fincas utilizan costosos sistemas de pivote central y movimiento lineal para regar la planicie de la meseta de la vieja Castilla. Estos sistemas utilizan la fuerza hidráulica del agua para mover el equipo y ahorrar mano de obra. Otros sistemas permanentes utilizan conductos que están a dos metros de profundidad para llevar el agua a desembocaderos que salen a los campos a distancias fijas.

En contraste, al norte del río Duero, los sistemas de riego por aspersión fueron introducidos más tarde, la mayoría en los años noventa. Familias de agricultores regaban pequeñas y medianas parcelas con redes de tuberías, desplazándolas cada ocho a diez horas dentro del campo, o con una red de tubería fija que cubría el campo entero y que permanecía en él durante la época de crecimiento. La economía agraria en el alto Duero expone muchas características de la agricultura campesina, como lo es la producción en pequeña escala, la dependencia de la mano de obra familiar y la supervivencia de regímenes agrarios medievales, como es el cambio de usos de campos privados a pastoreo comunitario después de levantada la cosecha. Sin embargo, la amplia presencia de maquinaria agrícola, el trabajo bajo contrato de cultivos industriales y el uso de insumos químicos son elementos que claramente indican la presencia de la agricultura industrial. La adopción de los

\footnotetext{
${ }^{1}$ Este trabajo está subvencionado por la National Science Foundation bajo la Beca No. BNS 8918981
}

Polígonos, no 9, 1999, pp. 117-143. 
sistemas de riego por aspersión por estos agricultores, que son un híbrido entre la agricultura tradicional y la industrial, merece una comparación con sus similares en otros países áridos y semiáridos al sur de Europa.

Este artículo presenta los resultados de una investigación sobre la adopción de sistemas de riego por aspersión utilizados por familias de agricultores de pequeña escala en el alto de la cuenca del río Duero. Primero se examinan los distintos patrones de difusión de los sistemas de riego por aspersión a través del tiempo y del espacio. Luego, se examina la influencia de las dos variables explicativas, la zona agroecológica y los atributos de cada hogar, ligadas a la adopción de nuevas tecnologías de regadío (CASWELL Y ZILBERMAN 1986; CASWELL 1991; FEDER Y UMALI 1993). Después, se compararan los procesos de adopción de estos agricultores campesinos/industriales españoles con los temas del agricultor industrial en la literatura más amplia sobre la adopción de nuevas tecnologías de regadío.

\section{SISTEMA DE RIEGO POR ASPERSIÓN EN LA CUENCA DEL RÍO DUERO.}

Entre 1955 y 1980 la cuenca del Duero lideró al resto de España en la expansión del regadío. El agua subterránea jugó un papel importante en este proceso y estuvo estrechamente ligada a la adopción del sistema de riego por aspersión. La mayoría de esta expansión ocurrió en la planicie de la meseta de Castilla la Vieja, cultivada bajo sistemas de agricultura bianual regada por la lluvia. Para convertir estas tierras en regadío, los agricultores debieron adoptar un método que distribuyera el agua subterránea por los campos. La irrigación por gravedad en surcos, el método de irrigación tradicional en España, requería campos nivelados y una red de canales y surcos. El costo de la mano de obra que implicaba preparar los campos de esta manera era considerable, especialmente cuando se le sumaban los altos costos que implicaba empezar a perforar pozos y de la adquisición de bombas. Los sistemas de riego por aspersión, en contraste, requieren menos mano de obra para preparar los campos, ya que éstos no necesitan ser nivelados o que se les hagan surcos.

Otras consideraciones son la eficiencia y los costos de operación. El agua que corre a través de canales abiertos y sin revestimiento está sujeta a altos niveles de evaporación y de filtración; además, revestir canales ocasiona grandes costos. En contraste, los sistemas de riego por aspersión son capaces de una distribución de agua muy eficiente $\mathrm{y}$, a pesar de que su adquisición es costosa, no requieren de mucha mano de obra para ser manejados. Una vez se encuentran instalados, los sistemas de riego por aspersión pueden dejarse en el mismo lugar y ser manejados automáticamente, sin necesidad de un control constante.

Este sistema requiere de mucho menos mano de obra que el riego por gravedad en surcos, que necesita de un control constante para asegurar que los campos estén regados de manera pareja y para evitar inundaciones o estancamientos. Los agricultores que quieren llevar sus campos irrigados al máximo potencial sembrando cultivos de alto costo y que requieren gran cantidad de agua, aprecian la capacidad que tienen los sistemas de riego por aspersión de asegurar la germinación por la distribución regular del agua sin perturbar la semilla, algo muy difícil de lograr 
con la irrigación por gravedad en surcos. Una germinación pobre o retrasada puede reducir drásticamente los ingresos en cultivos de alto costo y que requieren un riego intensivo.

Por esta razón, muchos agricultores decidieron utilizar el agua subterránea para convertir campos regados por la lluvia en campos regados artificialmente y adquirieron conductos de tubería enterrados e inmóviles o sistemas de pivote central de movimiento lineal, pues, a pesar de ser costosos, estos sistemas eran superiores al riego por gravedad en surcos. Cultivadores con acceso al agua de superficie también perforaron pozos y adquirieron sistemas de riego por aspersión. El agua subterránea permitía que los campos se regaran por adelantado, antes de disponer del agua almacenada en los embalses, y durante el periodo de crecimiento, cuando la entrega de agua es restringida. Los sistemas de riego por aspersión de pequeña escala operados manualmente y los que son fijos trabajan bien con aguas distribuidas por canal; las motobombas montadas en tractores pueden extraer agua de un canal, río o arroyo y distribuirla con la presión suficiente para mover los rociadores.

Cuadro 1. Motores de Riego en la Cuenca del Duero, 1962-1979.

\begin{tabular}{|c|c|c|c|c|c|c|c|c|}
\hline \multicolumn{7}{|c|}{ Motores de Riego, 1962-79 } & \multicolumn{2}{|c|}{ Gas-oil, 1979} \\
\hline \multirow[t]{2}{*}{ Provincia } & \multicolumn{2}{|c|}{ Numero } & \multirow{2}{*}{$\begin{array}{r}\text { Aumento } \\
62-79\end{array}$} & \multicolumn{2}{|c|}{$\begin{array}{c}\text { C.V. } \\
\text { media }\end{array}$} & \multirow{2}{*}{$\begin{array}{r}\text { Aumento } \\
62-79\end{array}$} & \multirow[t]{2}{*}{ Numero } & \multirow{2}{*}{$\begin{array}{l}\text { C.V. } \\
\text { media }\end{array}$} \\
\hline & 1.962 & 1979 & & 1962 & 1979 & & & \\
\hline Ávila & 2.878 & 7.524 & $161,4 \%$ & 2,9 & 11,3 & $289,7 \%$ & 2.688 & 26,4 \\
\hline Burgos & 1.172 & 1.795 & $53,2 \%$ & 4,1 & 4,4 & $7,3 \%$ & 391 & 7,5 \\
\hline León & 12.731 & 15.570 & $22,3 \%$ & 2,7 & 2,8 & $3,7 \%$ & 171 & 11,5 \\
\hline Palencia & 1.871 & 2.200 & 1 & 3,7 & 7,2 & 94,6 & 698 & 16 \\
\hline Salamanca & 3.130 & 6.695 & $113,9 \%$ & 2,2 & 8,8 & $300,0 \%$ & 2.841 & 17,8 \\
\hline Segovia & 2.471 & 5.750 & $132,7 \%$ & 2,5 & 8,0 & $220,0 \%$ & 1.934 & 18,6 \\
\hline Soria & 324 & 377 & $16,4 \%$ & 4,3 & 5,9 & $37,2 \%$ & 54 & 15,8 \\
\hline Valladolid & 8.022 & 14.314 & $78,4 \%$ & 3,3 & 8,7 & $163,6 \%$ & 4.545 & 20,9 \\
\hline Zamora & 6.076 & 9.406 & $54,8 \%$ & 2,8 & 6,4 & $128,6 \%$ & 2.487 & 15,3 \\
\hline Total & 38.675 & 63.631 & $64,5 \%$ & 2,9 & 7,0 & $141,4 \%$ & 15.809 & \\
\hline
\end{tabular}

Fuente: datos de MOLINERO (1982): Tabla IX p. 45

El primer CUADRO permite una mejor comprensión de la expansión de la irrigación con agua subterránea y de los sistemas de riego por aspersión de 1962 a 1979. Al comienzo de este período, León sobrepasaba a todas las demás provincias en número de sistemas de irrigación accionados con motobombas hidráulicas. La historia de la irrigación leonesa que promovió esto será explicada después, pero a partir de 1979 la situación cambió de manera drástica. Mientras León continuaba siendo la provincia con mayor número de sistemas de bombeo y el número había crecido en un $22,3 \%$ durante este período, su ritmo de crecimiento palidecía comparado con el de provincias localizadas al sur del Duero. Las provincias de Ávila, Salamanca y Segovia tenían bases mucho más reducidas en 1962, pero cada una tuvo un crecimiento de más del $100 \%$ en el número de sistemas, superando considerablemente a León. La provincia de Valladolid merece un comentario especial; 
de una base de 8.022 sistemas de bombeo en 1962 , su número creció $78,4 \%$ para así lograr un total de 14.314, aproximándose a León, que tenía 15.570. Este increíble incremento en las provincias de la cuenca del bajo Duero refleja un proceso de perforación acelerado, aunque tardío. Los regantes en estas regiones contaban con grandes cantidades de agua subterránea aptas para la utilización agrícola bajo los suelos arenosos, con poca capacidad de retener agua en sus tierras.

Los caballos de fuerza promedio requeridos para cada estación de bombeo son una medida que permite determinar el tamaño y de la capacidad de cada sistema. Durante el período que está siendo examinado, los bombeos se vuelven más potentes y de mayor capacidad: el número de caballos de fuerza promedio crece en un $141,4 \%$, o sea de 2,9 en el comienzo hasta 7 al final del período. La mayoría de este incremento puede ser atribuida a la adquisición de bombas diesel de alta capacidad, que podían distribuir grandes volúmenes de agua con la suficiente presión

para mover los aspersores. A pesar de que estos no fueron contados en 1962, había 15.809 bombas diesel en 1979, aproximadamente uno de cada cuatro sistemas de irrigación con agua subterránea. Las cifras más altas y las bombas diesel más potentes se encontraban en el sur del Duero, en las provincias de Ávila, Valladolid y Segovia, así como en Salamanca y Zamora. Los caballos de fuerza promedio en cada bombeo en estas provincias se incrementaron en más de un $100 \%$ y en tres se multiplicaron por dos o por tres. En contraste, la capacidad de bombeo en León solo creció un $3,7 \%$, de 2,7 a 2,8, un incremento que no era suficiente para que operaran los sistemas de riego por aspersión. Mientras que León sobrepasaba a las otras provincias en 1962 en el número y en los caballos de fuerza de sistemas de irrigación por bombeo, el promedio de sus caballos de fuerza de 2,7 era mucho mas bajo, indicando que el uso principal de estos en la provincia era de regar pequeños pedazos de tierra con agua que era distribuida por medio de surcos por gravedad.

La mayoría de este crecimiento explosivo en el número y la capacidad de las bombas y pozos también puede atribuirse a la reestructuración de las tierras, en particular, a la unión de pequeños minifundios en parcelas de mayor tamaño (ALARIO TRIGUEROS, 1991).

España promulgaba un gran programa en 1965, y poco después promulgó proyectos que reestructuraban la parcelación de la tierra y construía una infraestructura de vías, sistemas de drenaje y canales de alimentación (CABERO DIEGUEZ Y MAYA FRADES, 1990:279). Campos más grandes cambiaron el cálculo económico de irrigación subterránea por medio de un alivio en el pago de los altos costos que implicaba empezar a perforar pozos profundos. En 1985, la Comunidad Autónoma de Castilla y León lideró al resto de la nación en el total de tierras reparceladas (AlARIO TRIGUEROS 1991: Tabla 1, página. 86-87), otorgando muchas subvenciones a los agricultores, ofrecidas a través de varios programas gubernamentales para cubrir parcialmente los costos de la compra del equipo de riego.

\section{EL RÍO ÓRBIGO Y EL PÁRAMO.}

Para examinar en detalle la historia del regadío y de la adopción del sistema de riego por aspersión en el norte de la cuenca del Duero, se debe analizar antes la 
región del río Órbigo en la provincia de León. En esta zona, los agricultores han desviado el agua de los ríos tributarios que descienden de las montañas cántábricas y riegan las fértiles riberas aluviales por lo menos desde el siglo XIII. Al terminar el siglo, los agricultores de las riberas de los ríos Órbigo y Esla y de los páramos interfluviales fueron los pioneros en la extracción de agua subterránea. Inicialmente, los agricultores ribereños usaron cigüeñales, dispositivos que consisten en baldes atados a cañas con contrapeso, puestas sobre un trípode. Posteriormente, utilizaron norias, que son ruedas horizontales movidas mediante una palanca a la que va sujeta una caballería y otra rueda vertical engranada con la primera, la cual hace subir los cangilones llenos de agua. Esta agua se utilizó para regar los campos pequeños durante julio y agosto, meses en los que el agua de los ríos disminuía drásticamente. Tiempo después, los agricultores del Páramo adoptaron el método de riego con agua subterránea para transformar estas tierras (GUILLET, 1999a).

A pesar de que inicialmente el pequeño número de cigüeñales y norias no presentaba ningún peligro para las fuentes naturales de agua, con el tiempo sí lo presentaron. Bombas motorizadas más eficientes, capaces de sacar más agua a mayores profundidades que las norias, también se comenzaron a utilizar, incrementando aún más el excesivo bombeo de agua que había en ese momento. Al comenzar a secarse los pozos, los agricultores los abandonaban o continuaban profundizándolos para conseguir agua artesiana a un alto costo; para ello, perforaban un agujero estrecho al fondo del pozo hasta conseguir el volumen deseado de agua, insertando en este hueco una tubería recubierta de hierro para limitar el movimiento horizontal del agua y evitar su perdida por filtración. El agua artesiana que salía desde el fondo del pozo llegaba a la superficie por medio de una BOMBA (RUIZ IÑIGUEZ, 1912, 1923; INSTITUTO GEOLÓGICO Y MINERO DE ESPAÑA, 1980: 18).

En la década de los cincuenta, se construyó el embalse de Barrios de Luna, el cual proveía de riego continuo al Páramo y solucionaba las sequías de verano en la Ribera. La circulación de agua proveniente del embalse acentuaba pequeñas diferencias hidrológicas, lo cual llevó a la creación de dos zonas agroecológicas separadas en el Páramo, que fueron el Páramo Alto y el Páramo Bajo, divididas a lo largo de un eje nordeste-sureste aproximadamente a la latitud de Laguna Dalga. El agua del embalse irrigaba las tierras del Páramo Alto a través de una red de canales, pero a los campos distantes de los canales prin cipales muchas veces no les llegaba el agua. El agua salía de las zonas de recepción y desaguaba en el Páramo Bajo y al nordeste del Páramo Alto, alrededor del pueblo de San Pedro Bercianos. El agua de superficie que recibía el Páramo alteró las propiedades de la red de fuentes naturales de agua; los campos localizados en el Páramo Bajo y al nordeste del Páramo Alto eran regados esporádicamente con agua sobrante. Los agricultores de estas áreas perforaron pozos para compensar la s inseguras fuentes de agua de superficie. En algunos lugares, a éstas les llegaba el drenaje del Páramo 


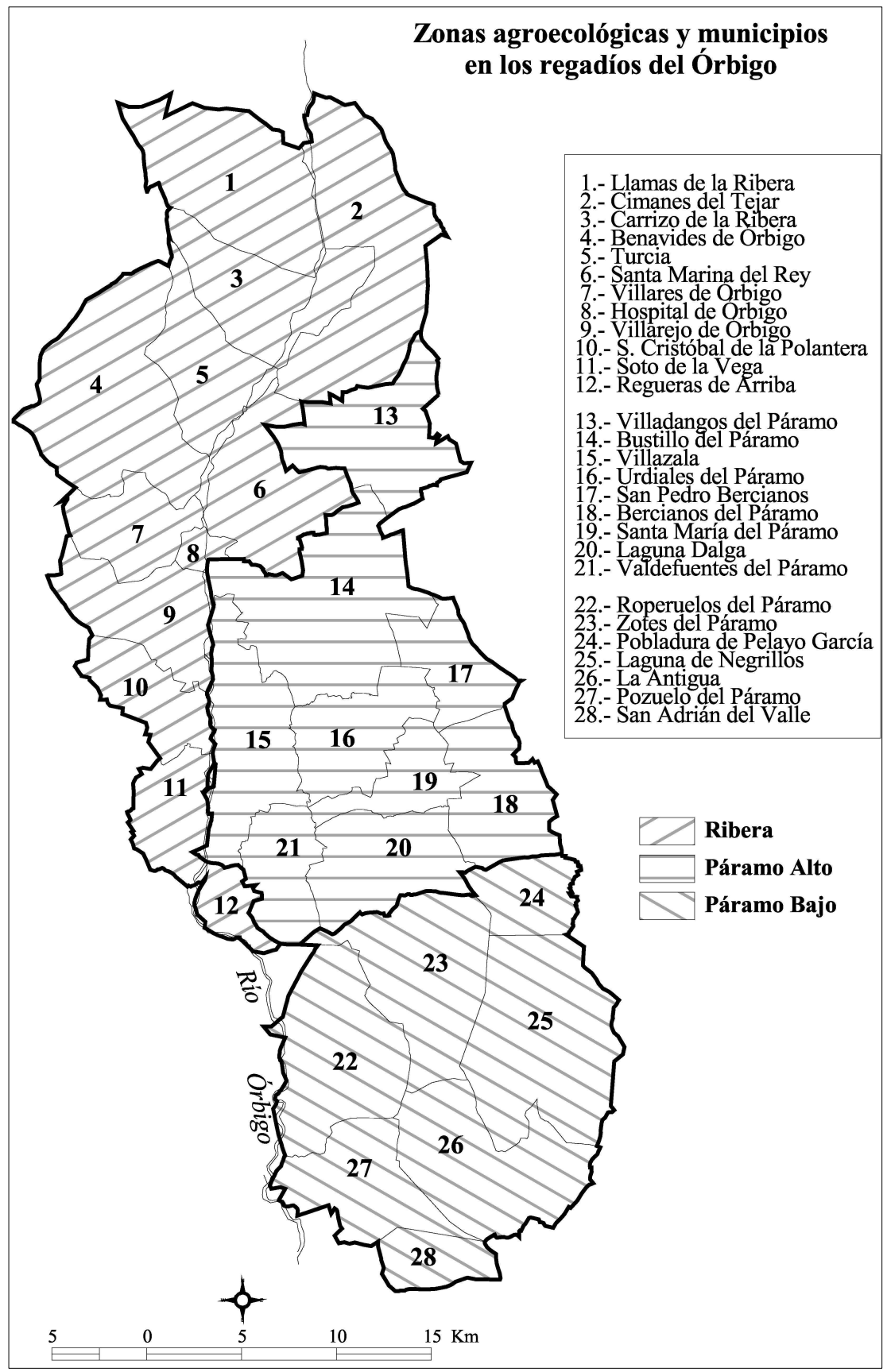


Alto, abasteciéndoles con suficiente agua subterránea para consolidarlas como fuentes de aguas seguras para el riego.

Cuadro 2. Método de Riego, 1989.

\begin{tabular}{|c|c|c|c|c|c|c|c|c|c|c|}
\hline & \multicolumn{2}{|c|}{ Total } & \multicolumn{2}{|c|}{ Aspersión } & \multicolumn{2}{|c|}{ Localizado* } & \multicolumn{2}{|c|}{ Gravedad } & \multicolumn{2}{|c|}{ Otros } \\
\hline Comarca & $\mathbf{N}^{\mathbf{0}}$. & Has. & $\mathbf{N}^{\mathbf{o}}$ & $\%$ & $\mathbf{N}^{\mathbf{0}}$. & $\%$ & $\mathbf{N}^{0}$. & $\%$ & $N^{0}$. & $\%$ \\
\hline Astorga & 4.795 & 9.846 & 41 & $0,9 \%$ & 23 & $0,5 \%$ & 4.692 & $97,9 \%$ & 165 & $3,4 \%$ \\
\hline La Bañeza & 3.175 & 12.214 & 32 & $1,0 \%$ & 46 & $1,4 \%$ & 3.114 & $98,1 \%$ & 109 & $3,4 \%$ \\
\hline Páramo & 4.337 & 34.544 & 138 & $3,2 \%$ & 44 & $1,0 \%$ & 4.153 & $95,8 \%$ & 174 & $4,0 \%$ \\
\hline Provincia & 36.782 & 107.039 & 1.270 & $3,5 \%$ & 566 & $1,5 \%$ & 35.355 & $96,1 \%$ & 1.102 & $3,0 \%$ \\
\hline
\end{tabular}

El CUADRO 2 presenta información del censo agrario de 1989 sobre los métodos utilizados para irrigar unidades de producción en la provincia de León y en las comarcas de Astorga, La Bañeza y el Páramo. Las comarcas de Astorga y La Bañeza incluyen aldeas y pueblos en las riberas agroecológicas de los ríos Órbigo y Tuerto. La comarca del Páramo reparte sus aldeas en las zonas agroecológicas del Páramo Alto y Bajo. Como se puede ver, la nueva tecnología de irrigación no estaba implementada en la mayoría de la provincia; el 96,1 \% de los campos agrarios eran irrigados por gravedad; las cifras del Páramo $(9,8 \%)$ y de las riberas de Astorga $(97,9 \%)$ y La Bañeza $(98,1 \%)$ son idénticas o un poco mayores. Los sistemas de riego por aspersión eran utilizados para regar algo mas del tres por ciento de los campos de regadío en la provincia y en el Páramo respectivamente, pero su impacto fue mucho menor en las riberas del Tuerto y el Órbigo (Astorga 0,9\%; La Bañeza $1 \%)$.

La demanda del agua se elevó a niveles nunca vistos en la década de los noventa a causa de un número de factores, tales como el crecimiento de la población, el cambio de pautas en el consumo de agua doméstica, la industrialización, el turismo, el aumento del ingreso per cápita y las normas ambientales de la Unión Europea. Pero la razón más inmediata y próxima que llevó a una crisis del agua fue una grave sequía entre 1992 y 1995. En 1992, el Ministerio de Obras Públicas y Transportes elaboró el anteproyecto de un decreto para tratar de aliviar la sequía persistente. A los entes del gobierno y a las autoridades de la cuenca se les concedió reducir las descargas de agua en las zonas donde la situación era mas crítica. (El País, 15 de Marzo de 1992). En respuesta a esto, la Confederación Hidrográfica del Duero (CHD) encargada del control del embalse de Barrios de Luna comenzó a administrar el agua de manera más conservadora, retardando el suministro, lo cual ocasionó un retraso en la siembra de cultivos y puso en riesgo los cultivos que requerían mucha agua. Para asegurar el bienestar de sus cultivos, muchos agricultores empezaron a contemplar un regreso al uso de agua subterránea para el riego y a considerar la idea de adquirir sistemas nuevos y más eficientes para utilizar las fuentes de aguas superficiales. 


\subsection{Encuesta de 1997 sobre el regadío con agua subterránea.}

La fuente principal de información para este estudio fue una encuesta sobre riego con agua subterránea que se efectuó en 1997 con 356 agricultores de dieciséis pueblos en la Ribera del Órbigo y en el Páramo (GUILLET, 1997). Los agricultores que participaron en la encuesta fueron seleccionados de las zonas agroecológicas de la Ribera, el Páramo Alto y el Páramo Bajo. La contribución de cada zona en relación con la población total de agricultores determinó el número que participó en la encuesta. Por ejemplo, si una zona tenía el $40 \%$ de la población total, el número de agricultores seleccionados de esta zona conformaba el $40 \%$ de los agricultores que participaron en la encuesta. Fueron 356 agricultores los que se entrevistaron, de los cuales 109 pertenecieron a la Ribera media, 142 al Páramo Alto y 105 al Páramo Bajo; partiendo de un total de 6.212 agricultores, de los cuales 2.573 son de la Ribera media, 1.982 son del Páramo Alto y 1.657 son del Páramo Bajo. Estas son cifras adecuadas y tienen un porcentaje de fiabilidad del $95 \%$.

Los objetivos de esta encuesta eran reconstruir la historia reciente del regadío con aguas subterráneas en la región y trazar las tendencias en curso en lo que concierne la adopción de sistemas de riego por aspersión. En este estudio, la variable dependiente es la adopción de sistemas de riego por aspersión, una variable dicotómica expresada en forma binaria, se indica con el número 1 si el agricultor adoptó este método de riego y con un 0 si esto no se dio. Las variables explicativas están divididas en dos grupos: las agroecológicas y las de cada hogar. Se ha mostrado que la zona agroecológica está consistentemente vinculada con la adopción de nuevas tecnologías de irrigación (CASWELL Y ZILBERMAN, 1986; CASWELL, 1991; FEDER Y UMALI, 1993). GLADWIN (1989:403) sugiere que los agricultores toman decisiones acerca de sus cultivos dependiendo más de las condiciones de la zona agroecológicas. Además, se ha demostrado que la calidad de la tierra, que está estrechamente vinculada con la zona agroecológica, es también un factor que tiene efecto sobre la adopción de tecnología de irrigación; por ejemplo, los agricultores que tienen una calidad de tierra pobre adoptarán estos nuevos métodos antes que los que tienen tierra de buena calidad (CASWELL, 1991; CASWELL Y ZILBERMAN, 1986). El término de zona agroecológica se refiere a una de las tres zonas en que se encuentra la residencia del agricultor, ya sea la Ribera, el Páramo Alto o el Páramo Bajo.

En el alto Duero, miembros de cada hogar trabajan en sus fincas y consumen e intercambian los bienes que éstas producen. Por lo general, estos agricultores toman decisiones basadas en las metas y necesidades del hogar, además de la tierra, la mano de obra, el capital, el agua, el crédito y la información que tienen a su disposición. Estos factores son los que determinan si la relación costo beneficio es lo suficientemente favorable como para justificar la adopción de una innovación. Los hallazgos de estudios sobre la adopción de nuevas tecnologías agrarias también demuestran que los atributos individuales de cada hogar son variables claves para explicar las diferencias individuales en la adopción (FEDER Y UMALI, 1993:215; GODOY, MORDUCH Y BRAVO, 1998:357; GODOY, FRANKS Y Claudio, 1998: 352-353). Para examinar estas, debemos seleccionar un número de variables explicativas demográficas y socio-económicas, como la edad, el nivel 
ocupacional, los cultivos sembrados, el tamaño de la finca, el estado respecto a la propiedad, el porcentaje de subvención y la posesión de un pozo en uso. La edad y el nivel ocupacional son indicadores de las fuerzas importantes para el cambio en el sector agrario de España (CALDERÓN CALDERÓN, CABALLERO FERNÁNDEZRUFETE Y DELGADO URRECHO, 1987; VIRUELA MARTÍNEZ, 1987). Por otra parte, la literatura más amplia dice que la elección del cultivo, el tamaño de la finca y el tipo de propiedad son los mayores determinantes en la adopción de nuevas tecnologías de irrigación (FEDER Y UMALI, 1993: 227, CASWELL, 1991). También se ha seleccionado el porcentaje de subvención para examinar el papel que juegan los incentivos financieros y la posesión de un pozo en uso como un vínculo entre los sistemas de riego por aspersión y la irrigación con agua subterránea.

\subsection{Dimensión temporal y espacial de los sistemas de riego por aspersión en la Ribera del Órbigo y el Páramo.}

La adopción de sistemas de riego por aspersión en León es un fenómeno reciente en comparación con la cuenca del bajo Duero. Solo ocho de las personas que participaron de la encuesta habían instalado estos sistemas antes de 1980, cifra que solo aumentó a veintiuno en 1990, a pesar de que aumentó de repente después de este año. Entre 1990 y 1997, periodo que se sobrepone con los años de sequía, 90 sistemas, o sea, un $81 \%$ del total, fueron instalados. Al final de este periodo, el $31 \%(n=111)$ de los agricultores de la encuesta habían instalado sistemas de riego por aspersión.

La zona agroecológica es significativa estadísticamente en la adopción del sistema de riego por aspersión ${ }^{2}$. Los agricultores del Páramo Bajo fueron los primeros en adoptarlo de manera significativa en la década de los setenta y durante ese período fueron adoptados la mayoría de los sistemas de riego por aspersión. En el Páramo Bajo, el 66,7\% de los agricultores adoptaron esos sistemas. El caso mas extremo fue el del pueblo de Pobladura de Pelayo García, donde el 88,6\% de los agricultores encuestados han adoptado esos sistemas de riego. Los agricultores del Páramo Bajo, como los agricultores de la cuenca del bajo Duero, opinan que los sistemas de riego por aspersión son el método más económico para distribuir el agua subterránea en los campos. En el control eficiente del agua, estos agricultores están mucho más motivados en este aspecto que los agricultores de la Ribera y del Páramo Alto, quienes han disfrutado, hasta muy recientemente, de suministros seguros de agua de superficie.

El Páramo Alto sigue en el número de sistemas de riego por aspersión que han sido adoptados, aunque estos agricultores quedaron atrás de los del Páramo Bajo hasta la década de los ochenta. En los resultados de la encuesta en el Páramo Alto, el 24,3\% de los encuestados habían adoptado este sistema. Algunas entrevistas que se hicieron a la par de la encuesta sugirieron que los agricultores del Páramo Alto estaban adquiriendo bombas fijas o móviles empujadas por tractor para distribuir el agua subterránea de pozos duraderos y/o el agua de superficie de los canales de riego. La Ribera ocupa una tercera posición muy distante en comparación con el

\footnotetext{
$\mathrm{x}^{2}=96,73, \mathrm{p} .<0.001$
} 
Páramo Alto y Bajo en relación con el número de sistemas adquiridos; sólo el $6,3 \%$ de la Ribera ha invertido en sistemas de riego por aspersión. Los agricultores se abstuvieron hasta la década de los noventa de adquirir estos sistemas y la adquisición permanece mínima, en cifras que son mucho menores a las del resto de la región. En varios pueblos de la Ribera no se puede encontrar un sólo sistema.

Cuadro 3. Adopción por Zona Agroecológica, 1970-1997.

\begin{tabular}{lrrrr}
\hline \multicolumn{1}{c}{ Pueblo } & $\mathbf{1 9 7 0 - 7 9}$ & $\mathbf{1 9 8 0 - 8 9}$ & $\mathbf{1 9 9 0 - 9 7}$ & Total \\
\hline Ribera & & & & \\
\hline Hospital de Órbigo & 0 & 0 & 0 & 0 \\
Santa Marina del Rey & 0 & 0 & 0 & 0 \\
Soto de la Vega & 0 & 0 & 4 & 4 \\
Vecilla & 0 & 0 & 0 & 0 \\
Veguellina de Órbigo & 0 & 0 & 1 & 1 \\
Villares de Órbigo & 0 & 0 & 2 & 2 \\
Subtotal & 0 & 0 & 7 & 7 \\
Porcentaje del Total & $0,0 \%$ & $0,0 \%$ & $7,8 \%$ & $6,3 \%$ \\
\hline
\end{tabular}

Páramo Alto

\begin{tabular}{lrrrr}
\hline Celadilla del Páramo & 0 & 0 & 4 & 4 \\
Fontecha & 0 & 0 & 3 & 3 \\
Puente de Hospital de Órbigo & 0 & 0 & 0 & 0 \\
Mozóndiga & 1 & 2 & 7 & 10 \\
Santa María del Páramo & 0 & 1 & 12 & 13 \\
Villadangos del Páramo & 0 & 1 & 2 & 3 \\
Villamor & 0 & 0 & 1 & 1 \\
\hline Subtotal & 1 & 4 & 29 & 34 \\
Porcentaje del Total & $12,5 \%$ & $30,8 \%$ & $32,2 \%$ & $30,6 \%$ \\
\hline
\end{tabular}

\section{Páramo Bajo}

\begin{tabular}{lrrrr}
\hline Laguna de Negrillos & 1 & 0 & 17 & 18 \\
Pobladura de Pelayo García & 6 & 7 & 18 & 31 \\
Zotes del Páramo & 0 & 2 & 19 & 21 \\
\hline Subtotal & 7 & 9 & 54 & 70 \\
Porcentaje del Total & $87,5 \%$ & $69,2 \%$ & $60,0 \%$ & $63,1 \%$ \\
\hline Total & $\mathbf{8}$ & $\mathbf{1 3}$ & $\mathbf{9 0}$ & $\mathbf{1 1 1}$ \\
\hline
\end{tabular}

Aunque la mayoría de los pueblos de la Ribera han pasado por la reestructuración del terrazgo, sus campos, cuyo tamaño promedio es de 0,7 hectáreas, son más pequeños que los del Páramo Alto (1,4 hectáreas) y que los del Páramo Bajo (3,1 hectareas), lo cual hace que se reduzcan los ingresos de capital para invertir en riego por aspersión en la Ribera. Los campos que son de tamaño reducido requieren de menos mano de obra para regar los campos por gravedad en surcos. Además, las asociaciones de riego de las riberas ejercen un control mayor sobre la distribución de agua de superficie que los sistemas de canales pertenecientes al Estado en el Alto Páramo. Existe un acceso más seguro al agua 
de superficie, lo cual disminuye para los agricultores de la Ribera el atractivo del riego por aspersión.

\subsection{Diferencias familiares en la adopción de sistemas de riego por aspersión.}

\section{Estado con respecto a la propiedad.}

La literatura más amplia sobre la adopción de tecnologías agrarias muestra resultados contradictorios sobre la relación entre el estado de tenencia de la tierra y la adopción de tecnologías. Sin embargo, hay estudios que sugieren que los agricultores que son dueños de las fincas están entre los primeros en adoptar estas nuevas tecnologías vinculadas a la tierra, como lo son el pozo profundo o los equipos de riego fijos (CASWELL, 1991: 300). La propiedad produce un interés en mantener una buena administración y productividad a largo plazo; los agricultores que a la vez son dueños de la tierra son más propensos a querer mejorar permanentemente sus tierras que los agricultores que no lo son.

La movilidad de los sistemas de riego manuales y fijos es una característica que distingue el riego por aspersión en la región del Órbigo. Los sistemas de pivote central y de movimiento lineal en el bajo Duero se mueven dentro del campo, pero son muy difíciles de desmontar, transportar y volver a armar en otro campo. Las tuberías, los sistemas de riego y los pozos que están bajo suelo son mejoras permanentes que se le hacen al campo. La diferencia entre las mejoras del riego movible y permanente así como la capacidad de penetración de este último en la Ribera del Órbigo y en el Páramo, explican porqué la información no logra sostener la relación estadísticamente significativa entre la forma de tenencia de la tierra y la adopción de los sistemas de riego. Los sistemas de riego por aspersión son adoptados independiente del estado de tenencia que se tenga, a pesar de que existen diferentes formas de tenencia de tierra en esta región. Según el Censo Agrario más reciente, que se llevó a cabo en 1989, el 36\% de la tierra cultivada en la provincia de León es alquilada; las cifras de la Ribera, el Páramo Alto y el Páramo Bajo son respectivamente del 47\%, 36\%, y el 35\% (INSTITUTO NACIONAL DE ESTADísTICA, 1991, pp. 1149-1152, Tabla 7). Los índices de alquiler son más altos en la encuesta que se llevó a cabo en el Órbigo. En esta muestra resultó que el 48,3\% de la tierra cultivada está bajo alquiler y las cifras correspondientes en la Ribera, el Páramo Alto y el Páramo Bajo son, respectivamente, de 68,7\%, 53,4\%, y $35,4 \%$. La encuesta realizada en el Órbigo indica que el $64,7 \%$ de los que respondieron alquilan la tierra y que las tierras alquiladas constituyen, en promedio, un $62,3 \%$ de las tenencias totales. 
Cuadro 4a. Zonas Agroecológicas y Variables Familiares.

\begin{tabular}{|c|c|c|c|c|c|c|c|c|c|}
\hline & \multicolumn{3}{|c|}{ Ribera } & \multicolumn{3}{|c|}{ Páramo Alto } & \multicolumn{3}{|c|}{ Páramo Bajo } \\
\hline & Si & $\mathrm{No}^{\mathbf{0}}$ & Todos & Si & No & Todos & Si & No & Todos \\
\hline \multicolumn{10}{|l|}{ Estatus ocupacional } \\
\hline Tiempo Parcial & 1 & 25 & 26 & 7 & 32 & 39 & 11 & 4 & 15 \\
\hline Tiempo Completo & 6 & 75 & 81 & 27 & 73 & 100 & 58 & 31 & 89 \\
\hline Todos & 7 & 100 & 107 & 34 & 105 & 139 & 69 & 35 & 104 \\
\hline \multicolumn{10}{|l|}{ Edad* } \\
\hline \multicolumn{10}{|l|}{ Todos Labradores } \\
\hline Edad Media & 41 & 57 & 56 & 43 & 56 & 53 & 56 & 61 & 58 \\
\hline Número & 7 & 104 & 111 & 34 & 106 & 140 & 70 & 35 & 105 \\
\hline \multicolumn{10}{|l|}{ Tiempo Parcial } \\
\hline Edad Media & 33 & 56 & 55 & 44 & 55 & 51 & 52 & 57 & 54 \\
\hline Número & 1 & 25 & 26 & 7 & 32 & 39 & 11 & 4 & 15 \\
\hline \multicolumn{10}{|l|}{ Tiempo Completo } \\
\hline Edad Media & 42 & 58 & 57 & 43 & 57 & 53 & 57 & 62 & 59 \\
\hline Número & 6 & 75 & 81 & 27 & 73 & 100 & 58 & 31 & 89 \\
\hline \multicolumn{10}{|l|}{ Cultivos } \\
\hline Remolacha & 7 & $\mathrm{~N} / \mathrm{A}$ & $\begin{array}{r}\mathrm{N} / \\
\mathrm{A}\end{array}$ & 31 & N/A & $\mathrm{N} / \mathrm{A}$ & 51 & N/A & N/A \\
\hline Otros & 0 & N/A & $\begin{array}{r}\mathrm{N} / \\
\mathrm{A}\end{array}$ & 2 & $\mathrm{~N} / \mathrm{A}$ & N/A & 19 & N/A & $\mathrm{N} / \mathrm{A}$ \\
\hline Hortalizas & 0 & N/A & $\begin{array}{l}\mathrm{N} / \\
\mathrm{A}\end{array}$ & 1 & N/A & N/A & 0 & N/A & N/A \\
\hline \multicolumn{10}{|l|}{ Tamaño expl. * } \\
\hline Menos de 10 has. & 2 & 78 & 80 & 7 & 54 & 61 & 15 & 16 & 31 \\
\hline 10-20 has. & 4 & 22 & 26 & 19 & 43 & 62 & 26 & 16 & 42 \\
\hline Mas de 20 has. & 1 & 2 & 3 & 8 & 9 & 17 & 29 & 3 & 32 \\
\hline \multicolumn{10}{|l|}{ Cambios en tamaño } \\
\hline Disminución & 0 & 12 & 12 & 3 & 14 & 17 & 6 & 3 & 9 \\
\hline Incremento & 6 & 38 & 44 & 21 & 26 & 47 & 30 & 7 & 37 \\
\hline \multicolumn{10}{|l|}{ Subvención } \\
\hline $\mathrm{Si}$ & 1 & N/A & N/A & 10 & N/A & N/A & 16 & N/A & N/A \\
\hline No & 6 & N/A & N/A & 24 & N/A & N/A & 54 & N/A & $\mathrm{N} / \mathrm{A}$ \\
\hline \multicolumn{10}{|l|}{ Pozo en uso* } \\
\hline $\mathrm{Si}$ & 7 & 101 & 108 & 15 & 85 & 100 & 6 & 3 & 9 \\
\hline No & 0 & 3 & 3 & 19 & 21 & 40 & 64 & 32 & 96 \\
\hline \multicolumn{10}{|l|}{ Razones } \\
\hline Reducir el riesgo & 5 & N/A & N/A & 23 & N/A & N/A & 26 & N/A & N/A \\
\hline Eficacia económica & 1 & N/A & N/A & 4 & N/A & N/A & 30 & N/A & N/A \\
\hline Mant. mano de obra & 0 & N/A & N/A & 6 & N/A & N/A & 13 & N/A & N/A \\
\hline
\end{tabular}


Cuadro 4b. Zonas Agroecológicas y Variables Familiares.

\begin{tabular}{|c|c|c|c|}
\hline & \multicolumn{3}{|c|}{ Todas las zonas } \\
\hline & Si & No & Todos \\
\hline \multicolumn{4}{|l|}{ Estatus ocupacional } \\
\hline Tiempo Parcial & 19 & 61 & 80 \\
\hline Tiempo Completo & 91 & 179 & 270 \\
\hline Todos & 110 & 240 & 350 \\
\hline \multicolumn{4}{|l|}{ Edad* } \\
\hline \multicolumn{4}{|l|}{ Todos Labradores } \\
\hline Edad Media & 51 & 57 & 55 \\
\hline Número & 111 & 245 & 356 \\
\hline \multicolumn{4}{|l|}{ Tiempo Parcial } \\
\hline Edad Media & 48 & 54 & 53 \\
\hline Número & 19 & 61 & 80 \\
\hline \multicolumn{4}{|l|}{ Tiempo Completo } \\
\hline Edad Media & 52 & 58 & 56 \\
\hline Número & 91 & 179 & 270 \\
\hline \multicolumn{4}{|l|}{ Cultivos } \\
\hline Remolacha & 89 & N/A & N/A \\
\hline Otros & 21 & N/A & N/A \\
\hline Hortalizas & 1 & N/A & $\mathrm{N} / \mathrm{A}$ \\
\hline \multicolumn{4}{|l|}{ Tamaño expl. * } \\
\hline Menos de 10 has. & 24 & 148 & 172 \\
\hline 10-20 has. & 49 & 81 & 130 \\
\hline Mas de 20 has. & 38 & 14 & 52 \\
\hline \multicolumn{4}{|l|}{ Cambios en tamaño } \\
\hline Disminución & 9 & 29 & 38 \\
\hline Incremento & 57 & 71 & 128 \\
\hline \multicolumn{4}{|l|}{ Subvención } \\
\hline $\mathrm{Si}$ & 27 & $\mathrm{~N} / \mathrm{A}$ & $\mathrm{N} / \mathrm{A}$ \\
\hline No & 84 & $\mathrm{~N} / \mathrm{A}$ & $\mathrm{N} / \mathrm{A}$ \\
\hline \multicolumn{4}{|l|}{ Pozo en uso* } \\
\hline $\mathrm{Si}$ & 28 & 189 & 217 \\
\hline No & 83 & 56 & 139 \\
\hline \multicolumn{4}{|l|}{ Razones } \\
\hline Reducir el riesgo & 54 & $\mathrm{~N} / \mathrm{A}$ & $\mathrm{N} / \mathrm{A}$ \\
\hline Eficacia económica & 35 & $\mathrm{~N} / \mathrm{A}$ & $\mathrm{N} / \mathrm{A}$ \\
\hline Mant. mano de obra & 19 & $\mathrm{~N} / \mathrm{A}$ & $\mathrm{N} / \mathrm{A}$ \\
\hline
\end{tabular}

$*$ significante $<.05$

El alquiler es una solución común a dos problemas. Por una parte, los altos índices de emigración a las ciudades hacen que los agricultores, dueños y trabajadores de sus fincas, salgan de sus aldeas y pueblos, creando la propiedad en ausencia (PÉREZ DÍAZ 1969). Por otro lado, algunos de los agricultores residentes prefieren alquilarlas porque esto requiere menos gasto de capital; además, por el tamaño y la ubicación de sus campos pueden ser alquilados con más facilidad en periodos de uno o varios años de acuerdo a las necesidades cambiantes de capital, 
mano de obra y herramientas con las que se cuenten. Las tecnologías de riego portátiles pueden transferirse de un campo a otro de acuerdo a los cambios en estas necesidades y de los ciclos de rotación de cultivos de cada campo.

\section{El estatus ocupacional}

El estatus ocupacional, en particular el cambio de trabajar en los cultivos a tiempo completo a hacerlo a tiempo parcial, es considerado como una de las mayores fuerzas de cambio en la agricultura de España. Más de uno de cada cinco de los encuestados era un agricultor a tiempo parcial. Siendo ésta una proporción considerable, las cifras de cultivadores a tiempo parcial son más altas en otros lugares de España. En la Comunidades Autónomas de Castilla y León, especialmente en la provincia de León, las alternativas diferentes a la agricultura se han desarrollado de una manera muy lenta y el mercado para jornaleros y trabajo asalariado dentro de la agricultura han sido bajos históricamente (VIRUELA MARTÍNEZ, 1987).

Se espera que los agricultores a tiempo completo hagan las inversiones de capital que aseguren y/o aumenten las ganancias y los ingresos de su hogar. Esto se puede percibir en los sistemas de riego por aspersión, ya que reduce la mano de obra, utiliza el agua de una manera más eficiente y ayuda a garantizar una cosecha exitosa para cultivos de alto costo y que requieren de mucha agua. De la misma manera, es menos probable que los agricultores a teimpo parcial inviertan en un sistema de riego por aspersión cuando la agricultura sólo contribuye en una porción del total de los ingresos del hogar. Algunos agricultores a tiempo parcial cercanos a jubilarse también estarían tratando de dejar la agricultura por completo, lo cual sería un incentivo menos para invertir capital en la finca. La falta de oportunidades de empleos que no estén relacionados con la agricultura en la región estudiada y los altos promedios de edad de las personas que participaron en la encuesta, parecen ser una mejor explicación para la presencia de agricultores a tiempo parcial.

Los resultados de este estudio todavía no pueden demostrar que la relación entre el estatus ocupacional y de adopción de tecnología sea estadísticamente significativa. Diecinueve de cada ochenta agricultores a tiempo parcial encuestados, o sea el $24 \%$, adoptan menos tecnología que los agricultores a tiempo completo, que son 91 de cada 270 , o sea el $34 \%$. Sin embargo, las cifras de adopción por parte de los agricultores a tiempo parcial siguen siendo considerables. Los agricultores a tiempo parcial pueden pasar la misma cantidad de tiempo en sus fincas que los agricultores a tiempo completo, pero se consideran sólo a tiempo parcial para poder obtener los beneficios del gobierno. La disminución en el uso de mano de obra a causa de los sistemas de riego por aspersión puede permitirle a los agricultores realizar otras actividades generadoras de ingreso. Por ejemplo, los agricultores a punto de jubilarse que pueden estar disminuyendo sus trababjos agrarios, pueden considerar que los sistemas de riego por aspersión son esenciales para cuando el agua subterránea sea su única fuente de agua para riego, como ocurre en el Páramo Bajo. Estos agricultores pueden considerar que los sistemas de riego por aspersión son una buena inversión cuando 
el gobierno otorgue ayuda financiera para los costos iniciales o pueden estar considerando dejárselo a sus herederos. Estos resultados irregulares merecen ser tema de estudio en el futuro.

\section{La edad}

La edad es otro de los aspectos más comentados con respecto a los cambios agrarios en Castilla y León. Los agricultores leoneses de la encuesta, con un promedio de edad de 55 años, eran mayores que los de otros lugares rurales de España. La edad de un agricultor podría afectar al deseo de invertir en innovaciones agrarias. Los agricultores que están más cercanos a la jubilación pueden estar disminuyendo la intensidad de su trabajo, mientras que los agricultores más jóvenes con familia tienen más probabilidad de operar su finca a tiempo completo. Cuanto más joven sea el agricultor, más probable es que acepte riesgos, ya que quedan mas años por delante para gozar de las ganancias de su inversión o para recuperarse de un fracaso. También es más probable que los agricultores jóvenes tengan mas educación y sean más abiertos a la innovación (FEDER Y UMALI, 1993:226).

La edad del agricultor es un factor determinante y de alto significado estadístico en la adopción de sistemas de riego por aspersión por parte de la población encuestada. Las variaciones en las zonas agroecológicas también merecen un comentario; los agricultores que adoptaron esta tecnología en el Páramo Alto y en la Ribera son de diez a quince años más jóvenes que los agricultores que tomaron parte de la encuesta en cada zona, mientras que los agricultores del Páramo Bajo que adoptaron los sistemas de riego por aspersión eran en promedio catorce años mayores que los de la Ribera y el Páramo Alto, estos todavía tenían la misma edad que los que respondieron a la encuesta en su respectiva zona. Las diferencias en edad de los agricultores que adoptaron los sistemas de riego en cada zona reflejan el dinamismo de sus respectivas economías. El Páramo Bajo es una región económicamente deprimida con una población ya alcanzando una edad madura, azotada por la emigración de sus habitantes jóvenes y mejor preparados. La Ribera y el Páramo Alto también tienen dificultad de encontrar y lograr que permanezcan, los agricultores jóvenes, pero la mayor productividad de sus regiones logra que se queden algunos, quienes representan la mayoría de los agricultores que han adoptado sistemas de riego por aspersión.

\section{Cultivos sembrados.}

La literatura más amplia informa que los agricultores con cultivos de alto valor tienen más probabilidad de adoptar nuevas tecnologías de irrigación (CASWELL, 1991). El valor de los cultivos y sus requerimientos de agua son determinantes importantes en la adopción de sistemas de riego por aspersión. Con pocas excepciones, por ejemplo la ocasional especialización en vegetales cultivados en invernadero, la mayoría de los agricultores cultivan una variedad de cultivos rotatorios (remolacha, maíz, alubias, legumbres, y alfalfa). De estos, la remolacha 
cultivada bajo contrato con procesadores de azúcar locales es el más lucrativo. Las azucareras, además de ser un comprador seguro para los agricultores, ofrecen insumos químicos y semillas altamente productivas, de alto contenido de azúcar, en condiciones muy favorables (MARRÓN GAITE, 1992, Tabla 18, pg. 75-76).

La producción exitosa de remolacha requiere un nivel de humedad alto y constante, para asegurar la germinación y un alto contenido de azúcar. Se estima que una cosecha de 50 toneladas métricas de raíces y hojas por hectárea requiere de 4,500,000 kilos de agua por hectárea. Esta cifra corresponde a 450 milímetros de lluvia anuales, asumiendo que esta humedad sea accesible a la planta. En comparación, el trigo necesita 250 milímetros y la alfalfa 800 milímetros anuales. La precipitación se pierde por evaporación, escorrentía, evapotranspiración e infiltración a profundidades más allá de la zona de las raíces. Tomando estas pérdidas en consideración, los observadores han calculado que los requerimientos reales de humedad para un cultivo de remolacha en la cuenca del Duero son de un mínimo de 700 milímetros anuales de precipitación (ALONSO-MUNOYERRO, 1986:62).

Además de los requerimientos anuales, la humedad debe estar distribuida a lo largo del año para corresponder con el ciclo vegetativo de la planta. La remolacha crece dentro de un período de seis meses, aproximadamente desde comienzos de abril hasta comienzos de octubre. Desafortunadamente, este período se sobrepone con la sequía del verano. Mientras que la planta requiere entre 360 y 450 milímetros de agua durante los meses de junio, julio y agosto, la lluvia durante estos meses oscila entre 109 milímetros en Burgos a 48 milímetros en Medina del Campo. En los meses previos a Abril y Mayo, se necesitan de 40 a 60 milímetros, mientras que en septiembre y octubre las cantidades óptimas son de 30 a 60 milímetros. La precipitación normal en la cuenca del Duero durante la primavera y el otoño normalmente logra cubrir las necesidades. Pero durante la sequía del verano, el riego debe abastecer la cantidad faltante, que esta entre 450 y 650 milímetros cúbicos por hectárea.

El riego por aspersión proporciona una distribución regular y una buena cobertura de agua para una buena y oportuna germinación. En realidad, el cultivo de remolacha esta estrechamente ligado con el riego por aspersión. El cien por cien de los agricultores de la Ribera que adoptaron este sistema siembran remolacha; las cifras correspondientes en el Páramo Alto y Bajo son de $91 \%$ y $73 \%$, respectivamente. Mientras que la rotación de cultivos y de campos hace que el vínculo entre los cultivos sembrados y el riego por aspersión sea difícil de medir, las entrevistas indican que los rociadores son puestos en los cultivos de mayor costo y los más sensibles al agua dentro del patrón de cultivos que se mantiene durante ese año. Estos suelen ser la remolacha, a no ser de que las estrategias de rotación de cultivos y campos impidan que se siembre este cultivo. Los agricultores de la Ribera y del Páramo Alto afirman que la probabilidad de que ellos adquieran rociadores disminuiría dramáticamente si no cultivaran remolacha bajo los acuerdos contractuales. 


\section{Tamaño de la explotación.}

Se ha comprobado que el tamaño de la explotación guarda una relación directa con la adopción de sistemas de riego por aspersión (CASWELL, 1991: 300). Cuanto más grande sea la explotación, más probable es que el agricultor decida invertir en estos sistemas. Los agricultores más adinerados tienen un mejor acceso a capital, crédito e información, factores estos determinantes para la adopción de riego por aspersión (FEDER Y UMALI, 1993: 227); además, ellos tienen una mayor capacidad de recuperación ante un fracaso. Las explotaciones pequeñas tienen menos posibilidades de invertir en un sistema de riego por aspersión, ya sea por los altos costos iniciales o por la dificultad en amortizar los préstamos. La información recogida en esta encuesta demuestra que las relaciones entre el tamaño de la explotación y la adopción de sistemas de riego por aspersión en todas las zonas agroecológicas son estadísticamente significativas ${ }^{3}$. La mayoría de los agricultores que adoptaron estos sistemas en la Ribera y en el Páramo Alto poseen entre diez y veinte hectáreas de tierra; en el Páramo Bajo, la mayoría logra cultivar áreas que superan las veinte hectáreas.

FEDER Y UMALI (1993:217) sugieren que los agricultores grandes adoptan los sistemas primero y que después de algún tiempo, ya pasada la incertidumbre, los adquieren los agricultores pequeños. Esta secuencia de grandes y pequeños agricultores es consistente con la amplia literatura acerca de la adopción de innovaciones. Cuando éstas son introducidas en una comunidad, algunos las adoptarán inmediatamente mientras que los demás tardan más en hacerlo, esperando a que salgan los resultados de la experimentación y la experiencia de quienes los adoptaron primero. De esta manera, aunque el nivel de riesgo se mantiene constante, quienes adoptan estos sistemas primero afrontan un nivel de incertidumbre mayor de quienes los adoptan después (CANCIAN, 1979). Además, los agricultores industriales pueden ser forzados a adoptar tecnología costosa para asegurar sus ganancias y para poder mantenerse competitivos ante otros agricultores (BARLETT, 1989).

El cambio en el tamaño de las explotaciones también es un indicativo de una explotación en fluctuación. Además de los ajustes en cantidad y tamaño de parcelas atribuibles a la consolidación de tierra, los cambios en la edad y la composición de la familia, ya sea de crecimiento o decrecimiento, también pueden provocar algunos cambios. Por ejemplo, si una explotación parece ser próspera, un agricultor puede invertir más dinero en la misma para asegurar el bienestar del hogar. Explotaciones que disminuyen en tamaño pueden ser indicación de emigración, jubilación, o dificultades financieras por parte de los miembros que la componen, lo cual desestimula la adquisición de nuevas tecnologías. En general, una explotación que se expande puede sugerir posibilidades de inversión y una que se contrae, lo opuesto. Existe información que comprueba esta apreciación: el 44,5\% de los agricultores con explotaciones que han crecido en los ultimos diez años han adquirido sistemas de riego por aspersión, comparados con un $23,7 \%$ de agricultores cuyas explotaciones han disminuido en tamaño. Por lo tanto, el aumento en el tamaño de las explotaciones es un factor estadísticamente significativo para la adopción de

${ }^{3} x^{2}=68,68, p .<.001$ 
estos sistemas ${ }^{4}$.

\section{Porcentaje de subvención}

Varios programas del gobierno han ofrecido subvenciones para tratar de cubrir parcialmente los costos de compra del equipo de riegos y se espera que estas subvenciones animen a los agricultores a invertir en sistemas de riego por aspersión. Cuanto más alto es el porcentaje de ayuda que se brinde, es más probable que el agricultor invierta en esta nueva tecnología. Mientras que la subvención no es estadísticamente significativa, se mantiene como un elemento importante en el cálculo de adopción de esta tecnología para muchos agricultores. Aproximadamente uno de cada tres agricultores que adoptan este sistema reciben alguna forma de subvención, donde la cuota inicial constituye un 36\% del costo de adquisición.

Pozo en uso.

Como ya se ha indicado, el agua subterránea en el lugar estudiado se utiliza tanto como un complemento al agua de superficie como una fuente primaria de agua para la irrigación. Se podría inferir, de un pozo en uso que se analizó durante este estudio, que el agua subterránea se utiliza en una de estas dos maneras y, como ya se ha visto, la irrigación con agua subterránea está asociada con distribución de agua por rociador aunque las funciones del sistema de riego por aspersión cambian de acuerdo al acceso de agua que se tiene disponible.

Una relación estadísticamente importante también se encontró entre la posesión de un pozo en uso y la adopción de tecnologías de riego por aspersión ${ }^{5}$. El 39\% de los agricultores encuestados poseían un pozo que estaba siendo utilizado y la mayoría vivía en una de las dos zonas agroecológicas del Páramo. Cada una de las tres zonas agroecológicas variaba en disponibilidad de agua de superficie y esta variación ayuda a explicar la conexión entre un pozo en uso y la adopción de un sistema de riego por aspersión. Donde el agua subterránea es la única fuente para el riego, los sistemas eficientes de regadío también son particularmente atractivos por ahorrar el agua que se saca constantemente de los pozos en donde existe el riesgo de sobrebombeo. Por esta razón, el 91\% de los que adoptaron estos sistemas de riego en el Páramo Bajo eran dueños de un pozo en uso. De manera contraria, cuando existía acceso al agua relativamente seguro, era menos probable que los agricultores compraran un equipo de riego costoso para conservar agua. Ninguno de los que adoptaron estos sistemas en la Ribera tenía un pozo en uso, mientras que un $56 \%$ de los agricultores que adoptaron este sistema en el Páramo Alto disponía de un pozo en uso.

\subsection{Discusión.}

Combinando las dos clases de variables explicativas, la zona agroecológica y

${ }^{4} \mathrm{x}^{2}=16,39 \mathrm{p}<, 001$

${ }^{5} \mathrm{x}^{2}=86,52 \mathrm{p}<, 001$ 
las características de cada hogar, se pueden establecer ciertas conclusiones acerca de los patrones temporales en la adopción de este tipo de riego. Primero, el Páramo Bajo sobresale entre las demás zonas por la rapidez y el alcance de la adopción de este tipo de riego. Los agricultores de esta zona fueron los primeros en instalar los aspersores y el número total de estos sistemas en esta zona sobrepasa con mucho a las otras dos. Se hace evidente que la edad y el tamaño de la explotación de estos agricultores también fueron factores importantes al tomar la decisión de adoptar estos sistemas, ya que el $53 \%$ de todos los agricultores que los adoptaron tenían entre 51 y 60 años y el $79 \%$ de estos tenían diez o más hectáreas de tierra ${ }^{6}$. Actualmente, los agricultores de edad intermedia o edad madura con tenencias de tierra medianas o grandes son los más inclinados a adoptar estos sistemas y representan una etapa más tardía y madura que le sigue a la innovación y experimentación de los primeros agricultores en adoptarlos. En esta zona, que es la peor de todas en cuanto a calidad de tierra y acceso al agua, el $43 \%$ de los agricultores logran una gestión eficiente de las aguas dada la instalación de sistemas de riego por aspersión.

Los agricultores del Páramo Alto empezaron a implementar los mismos sistemas del Páramo Bajo a comienzos de la década de los ochenta, adoptándolos de manera significativa en la década de los noventa. Esto se dio ya que, hasta principios de los noventa, estos agricultores contaban con una disponibilidad de agua del embalse Barrios de Luna relativamente segura y, por lo tanto, no necesitaban invertir en nuevas tecnologías para promover la conservación y el control más eficiente del agua, pero en los últimos años, cuando los retrasos en la distribución del agua de la embalse causados por escasez empezaron a afectar los cultivos causando una germinación pobre de la semilla de remolacha y un nivel bajo de azúcar en las cosechas, los agricultores de propiedades medianas comenzaron a adoptar sistemas de riego por aspersión para asegurar el éxito de sus cultivos. El 70\% de los encuestados expresaron que esta fue la razón principal por la cual decidieron adoptar estos sistemas. El tener un pozo productivo es un incentivo fuerte para adquirir estos sistemas, ya que permite a los agricultores regar sus campos antes de la llegada de agua de superficie; no obstante, para otros agricultores las mejoras en el rendimiento de la semilla a causa de estos sistemas y la facilidad de manejarlos a través de un canal desde una bomba montada en un tractor, fue motivo suficiente para adquirirlos. Estos son en su mayoría jóvenes empresarios agrícolas, con propiedades medianas, que tienen más capacidad de recuperarse de un fracaso que los agricultores con fincas más pequeñas. Los agricultores con propiedades grandes pueden no necesitar de la seguridad que representa el sistema de riego por aspersión ${ }^{7}$.

Los sistemas de riego por aspersión son relativamente nuevos para los agricultores de la Ribera, quienes no los adoptaron sino hasta la década de los

${ }^{6} \mathrm{x}^{2}=16,2 \mathrm{p}<, 001($ edad $) ; \mathrm{x}^{2}=86,52 \mathrm{p}<, 01$

${ }^{7}$ La edad $\left(x^{2}=29,65 \mathrm{p}<, 001\right)$, un pozo en uso $\left(x^{2}=29,65 \mathrm{p}<, 001\right)$, y el número de parcelas $\left(x^{2}\right.$ $=6,21 \mathrm{p}<, 05)$, son los factores que diferencian los agricultores que adoptan de los que no adoptan sistemas de riego por aspersión en esta zona. El Páramo Alto es la única zona agroecológica donde los pozos en uso y el numero de parcelas era un factor significativo. 
noventa y hasta el día de hoy sólo lo hacen en pequeña escala. Como sucede en el Páramo Alto, los jóvenes agricultores ribereños adoptaron sistemas de riego por aspersión de manera desproporcionada en las etapas tempranas de la adopción. En la Ribera, la edad, el tamaño de la explotación, y la forma de tenencia de la tierra también son factores importantes que diferencian los agricultores que adoptan el sistema de riego por aspersión y los que no ${ }^{8}$. Todos los agricultores que adoptaron estos sistemas en la ribera cultivan remolacha y todos poseen el $50 \%$ o menos de la tierra que cultivan, lo cual muestra que la Ribera es la única zona agroecológica en donde la forma de tenencia de tierra juega un papel importante. En comparación con los agricultores de las otras dos zonas, los agricultores que adoptaron este sistema en la Ribera son los que disponen de más recursos financieros. Cuatro de cada siete de los encuestados que adoptaron estos sistemas poseen entre diez y veinte hectáreas de tierra, comparado con el $73 \%$ de los encuestados en general cuyas propiedades son de menos de diez hectáreas y solo $24 \%$ logra tener entre diez y veinte hectáreas. Estos agricultores jóvenes y prósperos que adoptan estos sistemas tienen ventaja sobre el acceso a capital, crédito, información, tierra y por lo tanto representan el estrato empresarial de la Ribera. Sin embargo, no existen suficientes agricultores en la Ribera con estas características como para constituir una clase significativa de agricultores que adoptan estos sistemas. Además, los agricultores de la Ribera son mayores en edad y hay menos agricultores jóvenes, comparados en términos de edad con los del Páramo Alto y Bajo.

Los pozos ya no son una característica visible del panorama ribereño, ni son un factor determinante cuando se trata de la adopción de sistemas de riego por aspersión, como en el Páramo Alto, ya que el tener acceso relativamente seguro al agua de superficie no crea una necesidad en estos agricultores de adquirir tecnologías de riego eficientes, como lo son los sistemas de riego por aspersión, que economizan agua. Cinco de cada seis agricultores de la Ribera respondieron que la razón por la cual adoptaron estos sistemas fue la de reducir el riesgo de fracaso en sus cosechas. Mientras que otros agricultores con menos terreno parecían estar igualmente motivados, se resistían en invertir en estos sistemas debido a su desembolso inicial. Los agricultores con fincas más grandes se resistían a invertir en estos sistemas ya que la amplitud de sus tenencias les permitía elegir campo en el cual podían cultivar remolacha que los amortigüe de los problemas de retraso y escasez en la distribución del agua del embalse.

\section{CONCLUSIÓN.}

Los países áridos y semiáridos del sur de Europa están convirgiendo en la respuesta a las cambiantes políticas nacionales e internacionales de gestión de las aguas. La Unión Europea esta a punto de adoptar una nueva Regulación Marco para las Aguas diseñada para la reestructuración de lo que han sido sus normas hasta el momento y para establecer los objetivos en lo que concierne a las políticas

\footnotetext{
${ }^{8}$ Edad $x^{2}=12,53 \mathrm{p}<, 01$, tamaño de la explotación $x^{2}=9,14 \mathrm{p}<, 05$, tenencia de tierra $x^{2}=5,23$ $\mathrm{p}<, 05$
} 
de agua para el próximo siglo. Esto incluye la prohibición de descargas directas de residuos, con el fin de proteger el agua subterránea de la contaminación, el control del agua subterránea para detectar cambios en su composición química y la reversión de la contaminación inducida antropogénicamente. Para financiar estas medidas, el peso se pondrá sobre los que utilizan el agua subterránea (COMISIÓN EUROPEA, 1999). Esta "recuperación a costo total" coincide con la tendencia global de controlar la demanda del agua en vez de incrementar los suministros a través de la construcción cada vez más costosa de embalses y de otras instalaciones de abastecimiento de agua. El control de la demanda implica reconocer el valor del agua en relación con los costos de su provisión y la introducción de políticas que requieren que los consumidores ajusten su utilización más de acuerdo a estos costos. Las medidas para gestionar la demanda del agua incluyen los mercados de agua, los derechos, los cobros y los impuestos al agua transferible, calculados de acuerdo a la cantidad de agua consumida y a los costos punitivos por el despilfarro de la misma. Para los legisladores, el control de las aguas resulta atractivo, ya que une a sectores económicos de los países señalados en una relación estrecha con las fuerzas del mercado global. El costo de la extracción de agua subterránea se incrementará significativamente y se puede esperar que los sistemas de riego por aspersión sean adoptados con mayor frecuencia.

En España, los cambios en la gestión de la demanda pueden ser rastreados hasta el año 1986 con la Ley del Agua (GUILLET, 1999b; DEL MORAL Y SAURI, 1999). La Ley del Agua terminó con el tratamiento liberal del agua subterránea que se había dado durante más de cien años bajo la Ley del Agua de 1879. Se declaró que el agua subterránea era propiedad pública, se establecieron estrictos procedimientos para obtener concesiones para nuevos pozos y se le asignaron impuestos anuales a estas concesiones. Como resultado de los costos crecientes para la extracción de agua subterránea bajo la Ley del Agua de 1985, se vió interrumpida la expansión de esta actividad en la cuenca del Duero (MOLINERO HERNANDO, 1986). En 1996, el nuevo gobierno electo tomó más acciones respecto a la implementación del control de la demanda de agua. La muy esperada publicación, el Libro Blanco del Agua, realizada en diciembre de 1998, recomendó una serie de medidas para la mayor eficiencia en el uso de agua, para el manejo conjunto del agua de superficie y para el agua subterránea (MINISTERIO DE MEDIO AMBIENTE, 1998). Estas medidas crearon la expectativa de futuros incrementos en el costo de agua subterránea; mientras estos costos subían, el cambio a sistemas de riego por aspersión empezó a intensificarse. Se podrían esperar resultados similares en otros países del mediterráneo si se introdujesen estas medidas.

Este artículo pone de manifiesto una serie de preguntas sin respuesta que tienen que ver con el cambio de sistemas de riego por aspersión y que señala áreas factibles de estudiar en el futuro: cómo es el impacto de las nuevas tecnologías de irrigación sobre la hidrología local, particularmente en lo que concierne a la disponibilidad de agua de superficie y subterránea; en segundo lugar, los dramáticos cambios hidrológicos que siguen a la adquisición y aplicación de agua de riego ahora atraen la atención de los especialistas (TROUT, 1998: 298). 
La distribución de agua por el embalse de Barrios de Luna creó dos nuevas zonas agroecológicas: el Páramo Alto, área regada por esta agua y el Páramo Bajo, zona que se beneficia de las fuentes de agua recargadas y del exceso de agua de superficie que desagua del área anterior. La adopción de sistemas de riego por aspersión crea un impacto sobre la hidrología local en estas dos zonas en maneras que todavía no se ha terminado de estudiar. Sin embargo, la evidencia recogida a través de comentarios sugiere que la adopción de aspersores en el Páramo Alto está incrementando la carga sobre las fuentes de agua naturales y está mejorando el potencial de la irrigación con agua subterránea en el Páramo Bajo. Estos cambios en la hidrología local, asociados con las inversiones pasadas, enfocadas al aumento de reservas, a embalses de gran escala y a otras infraestructuras, como los nuevos sistemas de riego por goteo y por aspersión en otros lugares del mediterráneo, todavía no han sido investigados.

Un segundo asunto que el artículo pone de relieve es el grado en que divergen los agricultores parcialmente industrializados, con propiedades pequeñas y medianas, de los patrones establecidos en la literatura existente sobre la adopción de nuevas políticas de riego. La mayoría de los estudios hasta el momento están centrados en los agricultores industrializados de los Estados Unidos e Israel; se conoce muy poco sobre la respuesta del control de la demanda de agua de los agricultores parcialmente industrializados y con fincas de pequeña escala en áreas sensibles al agua en el Mediterráneo. La información que se presenta en este artículo muestra los paralelos entre el comportamiento de los agricultores españoles y el de los agricultores industrializados. La relación inversa en la región del Órbigo entre la facilidad de acceso al agua y la calidad de la tierra y la adopción del riego por aspersión refleja los hallazgos divulgados por varios investigadores (CASWELL Y ZILBERMAN, 1986; CASWELL, 1991; FEDER Y UMALI, 1993). El riego por aspersión tiene el nivel más alto de adopción en el Páramo Bajo, zona esta que tiene el acceso menos seguro de agua subterránea y la calidad más pobre de tierra. Los agricultores de la Ribera, con sus fértiles tierras aluviales y disponibilidad relativamente segura de agua, tienen el nivel más bajo de adopción. Todavía no se ha analizado a fondo la relación entre una calidad de tierra pobre con restricciones de productividad y textura, con acceso limitado al agua y la adopción de sistemas de riego por aspersión por parte de agricultores que tienen estas mismas condiciones en otros de los países áridos y semiáridos del sur de Europa. El peso de factores determinantes exclusivos de cada hogar, como lo es el tamaño pequeño de ciertas explotaciones, los altos costos del agua y de la mano de obra (FEDER Y UMALI, 1993: 221-223) también merece una investigación más amplia.

Para otros agricultores con un acceso más seguro al agua y a una mejor calidad de tierra, los sistemas de riego por aspersión son también una manera de asegurar la cosecha de cultivos de alto costo y que requieren mucha agua. En el Órbigo, los cultivos de remolacha están estrechamente vinculados al riego por aspersión, donde el 100\% de los agricultores de la ribera, 91\% del Páramo Alto, y $73 \%$ del Páramo Bajo utilizan este sistema. La agricultura por contrato de cultivos industriales también una alternativa para los agricultores españoles de pequeña escala. Las preguntas que quedan son: ¿Se adoptarán los sistemas de riego por 
aspersión para disminuir los riesgos de producción que existen al levantar estos cultivos bajo la irrigación? ¿Representa esto un vehículo para incrementar la eficiencia del uso del agua entre los agricultores mejor posicionados, que de otra forma no estarían motivados en conservar agua? Mientras que la información del Órbigo sugiere respuestas positivas para estas preguntas, paradójicamente parece ser que el futuro ofrece pocas oportunidades para que los cultivos de alto costo y altos requerimientos de agua induzcan la expansión de estos sistemas de irrigación. Por ejemplo, la remolacha está sujeta a las cuotas de la Política Agrícola Común desde el comienzo del régimen del azúcar en 1967. Esta política refleja un tratamiento más favorable a los alimentos producidos en el norte como lo son la leche, los cereales y la remolacha, que para los que son producidos en el sur (FENNELL, 1997: 134-168; 260-261). Se ve entonces que las metas de estas políticas trabajan con propósitos distintos. Mientras esto no debe ser motivo de sorpresa, debe ser una cuestión que se debe tener en consideración para la Directiva Marco de las Aguas en los países del Mediterráneo.

A pesar de que el tamaño de las explotaciones no es una cuestión significativa en la Ribera, su importancia varía a través de las demás zonas agroecológicas del Órbigo. En la adopción pionera de los sistemas de riego por aspersión por parte de los agricultores del Páramo Bajo en la década de los setenta, se da que los agricultores con explotaciones más grandes son los primeros en implementar esta tecnología (FEDER Y UMALI, 1993: 217). El tamaño de las fincas parece ser un factor que explica la demora de los agricultores pequeños por adoptar estos sistemas. En el Páramo Bajo, la adopción es mas acentuada que en cualquier otra zona y los agricultores con tenencias de todo tamaño han adoptado estos sistemas. Sin embargo, esta evidencia sugiere que el aumento de la eficiencia en los sistemas de riego por aspersión es un factor determinante en la adopción temprana de esta tecnología por parte de los agricultores del Páramo Bajo. De nuevo se resalta que la relación entre el tamaño de las explotaciones y la adopción de los sistemas de riego por aspersión merece más estudio.

Sin embargo, no todas las variables de hogar que fueron determinantes establecidos por otras personas tuvieron impacto en la región del Órbigo. Ni la tenencia de tierra ni el nivel ocupacional son estadísticamente significativas en estas zonas. La investigación señala que las tecnologías vinculadas a la tierra, como lo es el equipo de riego, tienden a ser adoptados primero por los dueños de las fincas que operan las mismas (CASWELL, 1991: 300). El hecho de que la información recogida en la región del Órbigo no logre sostener esta conclusión se puede atribuir a las peculiaridades del riego por aspersión. A pesar de que los rociadores pueden permanecer en los campos durante la época de riego, su movilidad es la principal atracción para los agricultores que dependen de la rotación de campos y cultivos. El ser agricultor a tiempo parcial o a tiempo completo no logra determinar la adopción de sistemas de riego por aspersión, aún cuando la necesidad de establecer un uso del agua más eficiente afecta por igual agricultores de medio tiempo y de tiempo completo.

Los agricultores con propiedades pequeñas o medianas que producen cultivos industriales y que no poseen una fuente de agua segura adoptan esta nueva tecnología de riego por aspersión primero, ya que les mejora la eficiencia en el uso 
del agua que disponen. Luego, los agricultores jóvenes con fincas medianas parecen adoptar estos sistemas ya que les da seguridad en la producción de su cultivo industrial. La ausencia de las mismas variables significativas a través de todas las zonas agroecológicas de la región del Órbigo puede dificultar que se constituyan políticas para promover y entender la difusión de las tecnologías de irrigación a través de todas las áreas de la región. Como las diferencias de ubicación pesan más que diferencias entre los hogares a la hora de adoptar los sistemas de riego por aspersión, las políticas utilizadas para difundir estas tecnologías y para la gestión eficaz del agua tienen que estar diseñadas específicamente para cada zona agroecológica.

La adopción de los sistemas de riego por aspersión parece ser alentador; representa una tendencia hacia el uso más eficiente de las aguas en una región antes confiada en el riego por gravedad y en un sector económico criticado por su despilfarro. Esta tecnología le resulta atractiva a muchos agricultores de pequeña escala; a diferencia de otros paquetes tecnológicos inapropiados para la producción a pequeña escala, estos están disponibles tomando en cuenta el factor de escala y a un precio accesible para agricultores de explotaciones pequeñas o medianas. Para aquellos a los que el costo inicial de estos sistemas es infranqueable, las subvenciones del gobierno son una consideración importante, pero se debe resistir caer en el optimismo excesivo. Mientras que algunos de los agricultores adoptan los sistemas de riego por aspersión como una medida explícita para administrar con economía el agua, otros lo ven como una forma de asegurar sus cultivos y la conservación del agua no se encuentra en su lista de preocupaciones, tal y como parece ser el caso para los legisladores de la Política Común Agrícola, juzgando por sus agendas.

\section{BIBLIOGRAFÍA.}

- AlARIO TRIGUEROS, Milagros (1991): Significado espacial y socioeconómico de la concentración parcelaria en Castilla y León. Madrid: Ministerio de Agricultura, Pesca y Alimentación.

- AlONSO-MUNOYERRO, JUSTO MORA (1986): «Sistemas de riego en Castilla y León». En: F. Sánchez López, Los Regadios de Castilla y León en el Marco de la CEE. Salamanca pp. 61-83.

- BARLETT, Peggy F. (1989): «Industrial agriculture». En: PLATTNER, STUART, ed. Economic anthropology. Stanford University Press pp. 45-61.

- CABERo DiÉGUEZ, Valentín y MAYA FRADES, Antonio (1989): «El páramo leonés». Fascículo 17 de La Provincia de León y sus comarcas. Diario de León pp. 266-280.

- Calderón Calderón, B., Caballero Fernandez-Rufete, P. Y DELGADO URRECHO, J.M. (1987): «La población». Geografia de Castilla y León. Tomo II. Valladolid: Ámbito.

- CANCIAN, Frank (1979): The Innovator's Situation: Upper-middle-class conservatism in agricultural communities. Stanford CA: Stanford University Press.

- CASWELL, M.F. (1991): «Irrigation technology adoption decisions: Empirical 
evidence». En: Ariel DINAR y David ZILBERMAN, eds. (1991) The economics and management of water and drainage in agriculture. Boston: Kluwer Academic Publishers pp. 295-312.

- CASWELl, M.F. Y ZILBERMAN, D. (1986): «The effects of well depth and land quality on the choice of irrigation technology». American Journal of Agricultural Economics 68:798-811.

- DEL MORAL, Leandro y David SAURÍ (1999): «Changing water policy in Spain». Environment 41:12-36.

- El País Madrid 15 Marzo de 1992.

- EUROPEAN COMMISSION (1999): Developments of the Water Framework Directive. http://europa.eu.int/water/water-framework/index_en.html.

- FEDER, GERSHON y Dina L. UMALI (1993): «The adoption of agricultural innovations: A review». Technological Forecasting and Social Change 43: 215239.

- FENNELL, Rosemary (1997): The common agricultural policy: Continuity and change. Oxford: Clarendon Press.

- GladwIN, Christina H. (1989): «On the Division of Labor Between Economics and Economic Anthropology». Stuart PLATTNER ed. Economic Anthropology. Stanford CA: Stanford University Press pp. 167-192

- GODOY, Ricardo, Jeffrey R. FRANKS y Mario AlvarAdo Claudio: «Adoption of Modern Agricultural Technologies by Lowland Indigenous Groups in Bolivia: The Role of Households, Villages, Ethnicity, and Markets». Human Ecology 26: 351-369.

- GodoY, Ricardo, Jonathan MORDUCH y David BRAVO (1998): «Technological Adoption in Rural Cochabamba, Bolivia». Journal of Anthropological Research 54: 351-371.

- GUILLET, David (1997): "Ground water irrigation and property rights in northwestern Spain». Political and Legal Anthropology Review 20: 144-163.

- GuILlET, David (1999a): «Reconsidering Institutional Change: Property Rights in Northwestern Spain». Paper presentado en la 3rd Annual Conference of the International Society for New Institutional Economics. Washington D.C. Sept. 17-18, 1999.

- GUILLET, David (1999b): «Spanish Water Law». En: Europe since 1945: An Encyclopedia. New York and London: Garland Publishers. En prensa.

- INSTITUTO GeOlÓGICO Y MINERO DE ESPAÑA (1980): Investigación hidrogeológica de la cuenca del Duero. Sistemas nos. 8 y 12: Plan Nacional de investigación de aguas. Madrid: Ministerio de Industria y Energía.

- InSTITUTO NACIONAL DE EstadístiCA (1991): León. Censo Agrario 1989. Tomo IV. Resultados comarcales y municipales. Madrid: Instituto Nacional de Estadística.

- MARRÓN GAITE, MARÍA Jesús (1992): La adopción y expansión de la remolacha azucarera en España. Madrid: Ministerio de Agricultura, Pesca y Alimentación.

- MiniSTERIO DE MEDIO AMBIENTE (1998): Libro blanco del agua en España. Madrid.

- MOLINERO HERNANDO, Fernando (1986): «El aprovechamiento de mantos 
freáticos en la Cuenca del Duero». Demanda y economía del agua en España. Alicante: CAM-Diputación Provincial de Alicante pp. 189-199.

- MOLINERO HERNANDO, Fernando (1982): El regadio: ¿una alternativa a la agricultura Castellano-Leonesa? Valladolid: Ámbito Ediciones.

- PÉREZ DÍAZ, Víctor (1969): Emigración y sociedad en la Tierra de Campos. Estudio de un proceso migratorio y un proceso de cambio social. Madrid: Escuela Nacional de Administración.

- Ruíz ÍÑIGUEZ, Ignacio (1912): Pozos artesianos. Valencia: Papelería de J. Gimeno.

- RUÍZ IÑIGUEZ, Ignacio (1923): Aguas subterráneas y pozos artesianos. Valencia: Talleres Tipográficos La Gutenberg.

- TROUT, Thomas (1998): «The impact of irrigated agriculture». Journal of Soil and Water Conservation 7:113-120

- VIRUELA MARTíNEZ, Rafael (1987): «Agricultura a tiempo parcial en España». Estudios Geográficos XLVII: 211-237.

RESUMEN: Los sistemas eficientes de distribución de aguas están siendo cada vez más reconocidos por su potencial para incrementar la agricultura sostenible en regiones áridas y semiáridas al sur de Europa. En España, los sistemas de riego por aspersión han sido adoptados ampliamente desde la década de los sesenta. La cuenca del río Duero es una de las regiones donde su uso ha sido más acentuado. Al sur del Duero, en donde predominan las grandes propiedades de tierra, los sistemas de pivote central y movimiento lineal permanentes han sido las técnicas más utilizadas. Al norte del Duero, donde las propiedades son más reducidas, las familias de agricultores prefieren los sistemas de riego manuales o fijos.

Este artículo trata de la adopción y el uso de sistemas de riego por aspersión por los agricultores en el norte del Duero, en el área del río Órbigo, en la provincia de León. Los datos recogidos provienen de una encuesta que se llevó a cabo en 1997 con 356 agricultores provenientes de dieciséis localidades. Se comprobó que las diferencias agroecológicas en cada lugar son el factor más determinante en la adopción del sistema de riego por aspersión. Distintas variables en cada hogar explican las diferencias individuales en el uso de éste. La sección que concluye este artículo evalúa el papel que juegan los sistemas de riego por aspersión de pequeña escala utilizados por las familias agricultores para la gestión sostenible de las aguas en el sur de Europa.

PALABRAS CLAVE: riego por aspersión, España, agricultura familiar, gestión de las aguas.

ABSTRACT: Increasingly, more efficient water distribution systems are being hailed for their potential in increasing the sustainability of land use in the arid and semi-arid areas of southern Europe. In Spain, sprinkler irrigation systems have been adopted widely since the 1960's. One of the regions where their use has been most pronounced is the watershed of the Duero river. South of the Duero where large size holdings predominate, center pivot, linear move and permanent systems are the technique of choice. North of the Duero, where holdings are much smaller, family farmers prefer hand moved or solid set systems. This article addresses the adoption and use of sprinkler systems by family farmers north of the Duero in the region of the Órbigo river in the province of Leon. Data come from a survey conducted in 1997 of 356 farmers in sixteen villages and towns. Agro-ecological 
differences are found to be the most important determinant of locational variation in the adoption of sprinkler irrigation. Household variables, in turn, explain individual differences. A concluding section assesses the role of small-scale sprinkler irrigation systems by family farmers in the sustainable management of water in southern Europe.

KEY WORDS: sprinkler irrigation, Spain, family farming, water management.

RÉSUMÉ: Les systèmes efficients de distribution des eaux sont de plus en plus reconnus pour leur potentiel à accroître l'agriculture soutenue dans des régions arides ou semiarides du sud de l'europe. En espagne, les systèmes d'arrosage par aspersion ont été amplement adoptés depuis les années soixante. Le bassin du Douro est l'une des régions où son utilisation est la plus marquée. Au sud du Douro, où prédominent les grandes propriétés terriennes, les systèmes de pivot central et de mouvement linéaire permanents ont été les techniques les plus utilisées. Au nord du Douro, où les propriétés sont plus réduites, les familles d'agriculteurs préfèrent les systèmes d'arrosage manuels ou fixes.

Cet article parle de l'adoption et de l'utilisation de systèmes d'arrosage par aspersion par les agriculteurs dans le nord du Douro, dans la zone du fleuve Órbigo, dans la province de León. Les données recueillies proviennent d'une enquête réalisée en 1997 avec 356 agriculteurs provenant de seize localités. On a vérifié que les différences agricoles et écologiques de chaque lieu sont le facteur déterminant dans l'adoption du système d'arrosage par aspersion. Différentes variables dans chaque foyer expliquent les différences individuelles dans l'utilisation de celui-ci. La section qui conclut cet article évalue le rôle que jouent les systèmes d'arrosage par aspersion à petite échelle utilisés par les familles d'agriculteurs pour la gestion soutenue des eaux dans le sud de l'europe.

MOTS-CLÉS: arrosage par aspersion, Espagne; agriculture familiale, gestion des eaux. 